\title{
sensors
}

ISSN 1424-8220

(C) 2005 by MDPI

http://www.mdpi.orgt/sensors

\section{Nitric Oxide Detection with Glassy Carbon Electrodes Coated with Charge-different Polymer Films}

\author{
Osamu Ikeda *, Kumiko Yoshinaga and Jianping Lei \\ Department of Chemistry, Faculty of Science, Kanazawa University, Kakuma, Kanazawa, Ishikawa 920-1192, \\ Japan
}

* Author to whom correspondence should be addressed. E-mail: osamu@kenroku.kanazawa-u.ac.jp

Received: 9 June 2004 / Accepted: 28 October 2004 / Published: 26 April 2005

\begin{abstract}
Trace amounts of nitric oxide (NO) have been determined in aqueous phosphate buffer solutions ( $\mathrm{pH}=7.4)$ by using a glassy carbon electrode coated with three charge-different polymer films. The glassy carbon electrode was coated first with negatively charged Nafion film containing tetrakis(pentafluorophenylporphyrin) iron(III) chloride (Fe(III)TPFPP) as the NO oxidation catalyst, and then with positively charged poly(acrylamide-co-diallyldimethylammonium chloride) (PADDA) and with neutral poly(dimethylsiloxane) (silicone) at the outermost layer. This polymer-coated electrode showed an excellent selectivity towards NO against possible concomitants in blood such as nitrite, ascorbic acid, uric acid, and dopamine. All current ratios between each concomitant and NO at the cyclic voltammogram was in $10^{-3} \sim 10^{-4}$. This type of electrode showed a detection limit of $80 \mathrm{nM}$ for NO. It was speculated from the electrochemical study in methanol that high-valent oxoiron(IV) of Fe(TPFPP) participated in the catalytic oxidation of NO.
\end{abstract}

Keywords: polymer-coated electrode, nitric oxide detection, tetrakis(pentafluoro-phenylporphyrin) iron(III) chloride.

\section{Introduction}

Nitric oxide (NO) plays significant roles in the microbiology, physiology and chemistry of an environment. Since NO itself became to be known as an endothelial-derived relaxing factor [1,2], it has been clarified that NO 
worked as a neurotransmitter in the brain [3], and as an antitumor agent [4]. The determination of NO in biological media is of great importance but it is complicated by the short life due to the high reactivity of NO. Several methods have been implemented for measuring NO [5]. Among these methods, the electrochemical one is the most suitable for in-situ NO detection. Direct electrochemical reduction or oxidation of NO can be achieved on bare metals or carbon materials [6,7]. However, many substances, which disturb the detection of NO, are present in vivo. Coating of the electrodes with a Nafion membrane prevents side reaction of nitrite oxidation, but can not prevent the interference by positively charged substance in blood, for example, dopamine. In order to improve the selective detection of NO, several polymer films have been coated onto base electrodes, and are summarized in Bedioui and Villeneuve's review [8]. In these polymer films, WPI membrane [9] has been shown to be effective for selective NO detection, but the nature of the membrane is not indicated. Single layer membrane on electrodes $[10,11]$ has been claimed to be effective for selective detection of NO, we tried to prepare an electrode coated with three charge-different polymer films and checked its performance for the selective detection of NO. Since Malinski and Taha [12] first clarified that electropolymerized Ni(II)porphyrin was effective for the high-sensitive detection of nitric oxide, many metalloporphyrins [13-20] had been investigated to clarify their functions in the catalysis. Present authors also studied on various iron porphyrins [18] and found that tetrakis(pentafluorophenylporphyrin) iron(III) chloride (Fe(TPFPP)Cl) was an excellent catalyst for nitric oxide oxidation. We utilized this porphyrin as the oxidative detection of nitric oxide in this work.

\section{Experimental}

\section{Chemicals}

As the polymer for electrode coating, negatively charged Nafion alcoholic solution (Aldrich, $5 \mathrm{wt} \%$ ), positively charged poly(acrylamide-co-diallyldimethylammonium chloride) (PADDA) aqueous solution (Aldrich, $10 \mathrm{wt} \%$ ), and neutral poly(dimethylsiloxane) in xylene (Toray-Dow, KE-9140, $60 \mathrm{wt} \%$ ) were used. The latter two solutions were diluted to $5 \mathrm{wt} \%$ and $10 \mathrm{wt} \%$ with the original solvent, respectively.

Nitric oxide (NO) (Nippon Sanso) diluted with $\operatorname{Ar}$ (5\% NO) was bubbled into the electrochemical cell for $20 \mathrm{~min}$. The concentration of NO in solutions was estimated to be $87.5 \mu \mathrm{M}$ [5]. The NO solutions with lower concentrations than $87.5 \mu \mathrm{M}$ were prepared by adding a constant amount of the above solution into $10 \mathrm{ml}$ phosphate buffer in a glove box filled Ar. Ar gas for purging dissolved oxygen in electrolytic solution and in $5 \% \mathrm{KOH}$ for purification line of NO was of ultra-pure (Nippon Sanso, 99.9999 \%). This gas was passed for 30 min before passing NO.

\section{Preparation of Electrode}

A glassy carbon rod with $3 \mathrm{~mm} \phi$ embedded in a phenol resin pipe with $6 \mathrm{~mm} \phi$ was used as the electrode. The electrode was cleaned by polishing with $0.06 \mu \mathrm{m}$ alumina and then washing in an ultrasonic bath. The surface was at first coated with a known volume of Nafion solution (5 wt\%) as to be $16 \mu \mathrm{m}$ after drying, and 
next with an aqueous solution of PADDA (5 wt\%), and finally with a xylene solution of silicone (10 wt\%), as shown in Fig. 1. This coating order was selected to avoid mixing of each two polymers. In the estimation of film thickness, volume of polymer solution, coating area, and the density of polymer in solid state were taken into account. The density of polymer has been assumed to be 1.0 for Nafion, 1.2 for PADDA, and 1.0 for silicone, respectively, on the basis of each technical data. Fe(TPFPP) as the NO oxidation catalyst was originally dissolved in the Nafion solution, and the concentration was adjusted to $10 \mathrm{nmol}$ per dried Nafion $1 \mathrm{mg}[18]$.

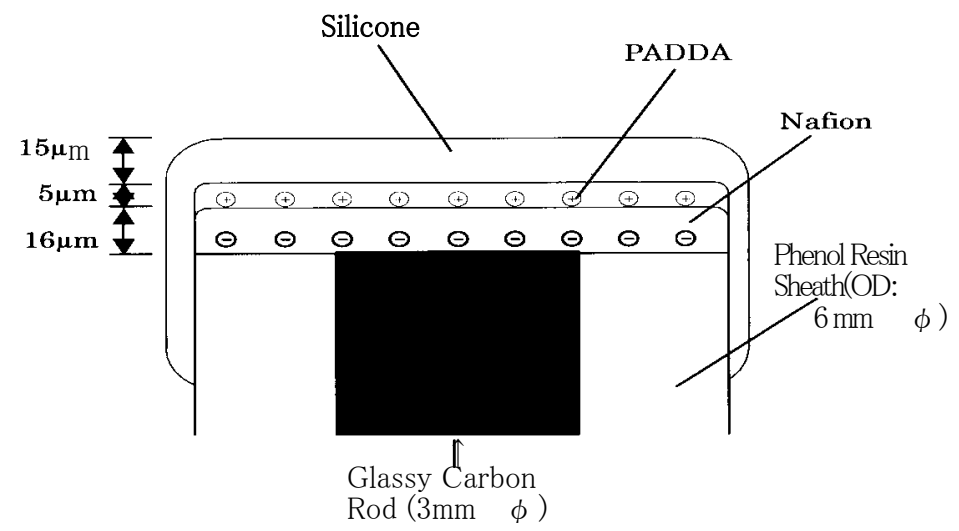

Figure 1. Structure of a glassy carbon electrode coated with charge-different polymer films.

\section{Electrochemical Measurements}

Electrochemical measurements were carried out in a one-compartment cell with three electrodes by using an electrochemical analyzer (BAS, model 100B/W). A glassy carbon disk $\left(0.071 \mathrm{~cm}^{2}\right)$ coated with polymer films, an $\mathrm{Ag} \mid \mathrm{AgCl}$ in $3 \mathrm{M} \mathrm{NaCl}$ (all potential values are given against this electrode), and Pt plate were used as working, reference, and counter electrode, respectively. Cyclic voltammograms of water-insoluble $\mathrm{Fe}$ (TPFPP)Cl was done in $0.1 \mathrm{M}$ methanol solution of tetrabutylammonium perchlorate (TBAP). A Ag| $\mathrm{Ag}^{+}$was used as the reference electrode in this solution. The potential was $0.20 \mathrm{~V}$ against the above $\mathrm{Ag} \mid \mathrm{AgCl}$ electrode. Effect of hydroxide on the cyclic voltammograms of $\mathrm{Fe}(\mathrm{TPFPP}) \mathrm{Cl}$ was examined by adding small amount of tetrabutylammonium hydroxide aqueous solution.

\section{Results and Discussion}

Effect of the Thickness of Polymer Film

We determined the most suitable film thickness of three charge-different polymers as following. Suitable film thickness of Nafion for NO detection has already been studied in Ref. [18], and is found to be $16 \mu \mathrm{m}$. This thickness was utilized in the present study. Then, we checked the second layer of positively charged PADDA 
by changing the thickness under the fixed thicknesses of Nafion $(16 \mu \mathrm{m})$ and silicone $(15 \mu \mathrm{m})$. Suitable film thickness of PADDA was determined by the electrochemical reaction of dopamine as a possible interfering substance in vivo.

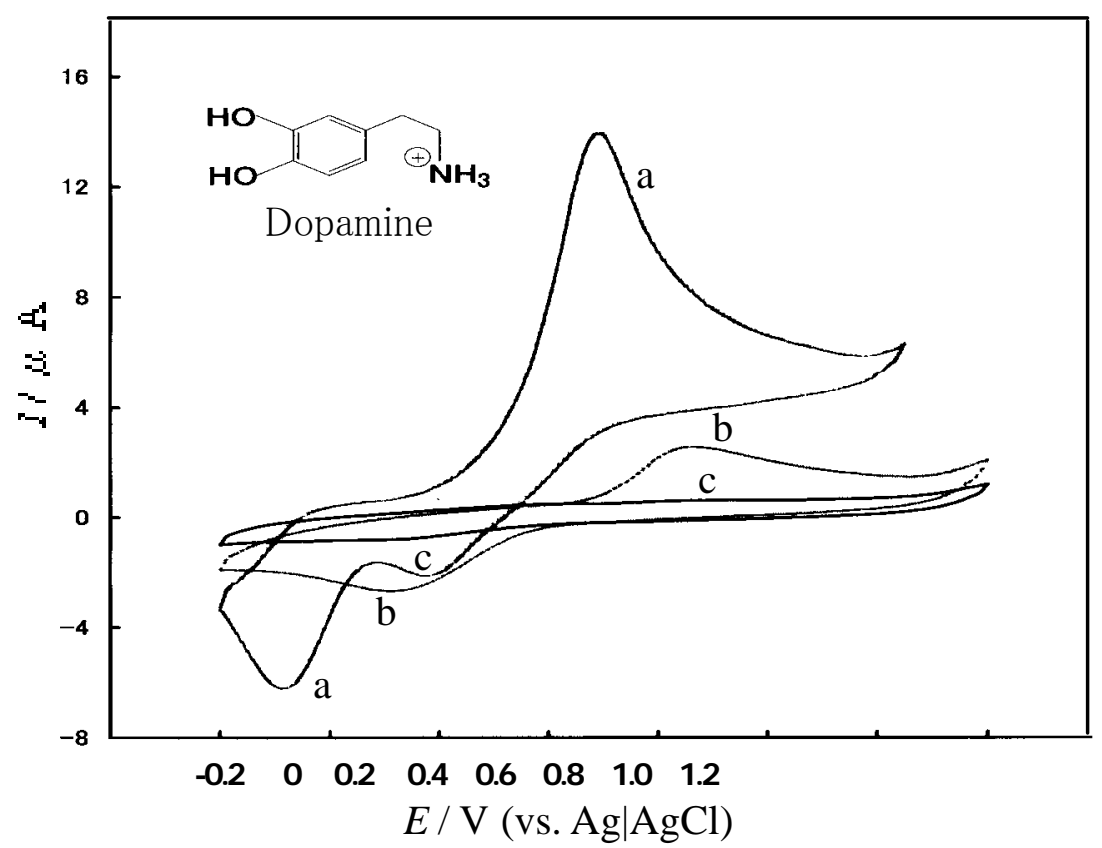

Figure 2. Cyclic voltammograms of $1 \mathrm{mM}$ dopamine in $50 \mathrm{mM}$ PBS ( $\mathrm{pH}=7.4)$ at a bare GC (a) and at a GC) Nafion $(16 \mu \mathrm{m}) \mid$ PADDA (b, $3 \mu \mathrm{m}$; c, $5 \mu \mathrm{m}) \mid$ Silicone (15 $\mu \mathrm{m})$ electrode. Scan rate, $20 \mathrm{mV} \mathrm{s}^{-1}$.

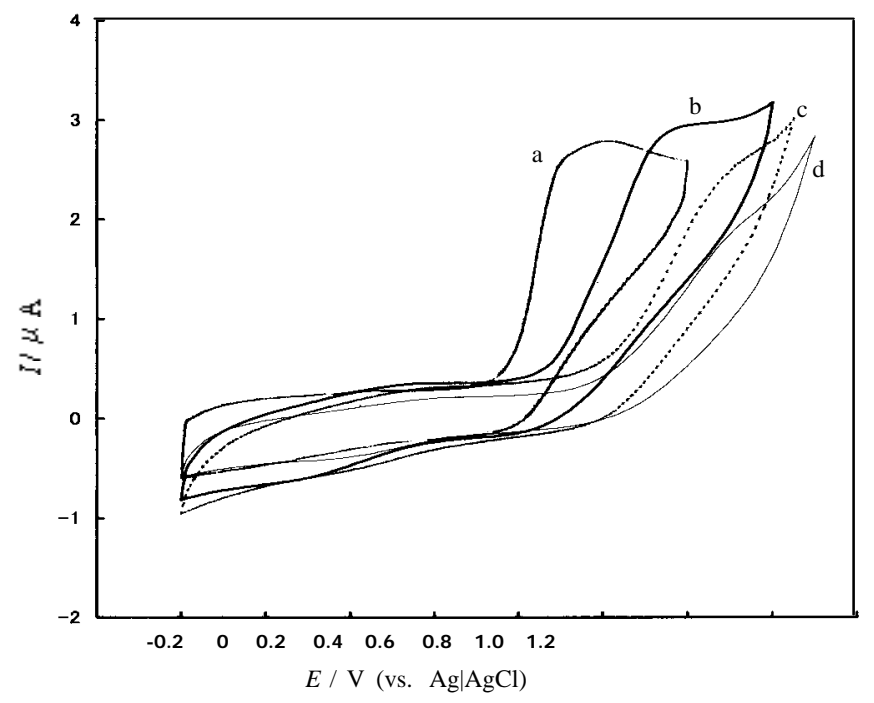

Figure 3. Cyclic voltammograms of $87.5 \mu \mathrm{M}$ NO in $50 \mathrm{mM}$ PBS ( $\mathrm{pH}=7.4)$ at a GC | Nafion(16 $\mu \mathrm{m})(\mathrm{a})$, and at a GC|Nafion (16 $\mu \mathrm{m})$ | PADDA (5 $\mu \mathrm{m})$ |silicone (b, $15 \mu \mathrm{m}$; c, $23 \mu \mathrm{m}$; d, $46 \mu \mathrm{m}$ ) electrode. Scan rate, $20 \mathrm{mV} \mathrm{s}^{-1}$. 
Figure 2 shows the result. PADDA of $3 \mu \mathrm{m}$ thickness (Fig. 2a) could not inhibit the penetration of dopamine, but $5 \mu \mathrm{m}$ thickness (Fig. 2b) were able to completely inhibit its penetration. The thickness more than $5 \mu \mathrm{m}$ showed almost the same cyclic voltammogram as that of $5 \mu \mathrm{m}$.

On the other hand, thin silicone film is necessary for high sensitive detection of NO. However, the film thickness below $15 \mu \mathrm{m}$ showed many cracks on the film. So, an effect of the thickness on NO detection was studied by preparing following electrode: GC | Nafion $(16 \mu \mathrm{m}) \mid$ PADDA $(5 \mu \mathrm{m}) \mid$ silicone with different thickness. The result is shown in Fig. 3. Increasing in the thickness gave decreased response to the NO oxidation. As the result, we selected $15 \mu \mathrm{m}$ for the silicone film at the outermost layer.

\section{Selective Detection of NO}

By using the above polymer film-coated GC electrode, it was checked the selectivity of NO for nitrite, dopamine, ascorbic acid, and uric acid as possible concomitants in vivo. The cyclic voltammograms of $1 \mathrm{mM}$ each concomitant on bare GC, on GC|Nafion $(16 \mu \mathrm{m})$, and on GC|Nafion $(16 \mu \mathrm{m}) \mid$ PADDA $(5 \mu \mathrm{m})$ |silicone $(15 \mu \mathrm{m})$ electrode were measured. In this experiment, negatively charged nitrite, ascorbic acid, and uric acid were completely deactivated on (b) Nafion-coated GC electrode. On the other hand, positively charged dopamine was not deactivated at a GC|Nafion electrode, in which the oxidation peak potential in the cyclic voltammogram was shifted from $0.2 \mathrm{~V}$ to $0.5 \mathrm{~V}$ (vs. $\mathrm{Ag} \mid \mathrm{AgCl}$ ) by the Nafion coating, but the peak current and the shape of wave were almost the same as those at a bare GC. However, dopamine was almost deactivated on the triply polymer film-coated GC electrode, as has already been shown in Fig. 2c.

Performance of the GC|Nafion|PADDA|silicone electrode was summarized in Table 1. Each oxidation peak current has been evaluated by subtracting the base current without the substance. An effect of four possible concomitants on NO detection was found to be almost negligible at the present triply polymer-coated electrode.

Table 1. Oxidation peak currents of NO and interfering compounds observed at a bare and at a triply polymer film-coated GC electrode and their ratio.

\begin{tabular}{c|c|c|c}
\hline \multirow{2}{*}{ Compound } & \multicolumn{2}{|c|}{$\begin{array}{c}\text { Oxidation Peak Current at } \\
\text { Different Electrodes } \\
/ \mu \mathrm{A}\end{array}$} & $\begin{array}{c}\text { Peak Current } \\
\text { Ratio between } \\
\text { (a) and (b) }\end{array}$ \\
\cline { 2 - 3 } & $\begin{array}{c}\text { (a) Bare } \\
\text { GC }\end{array}$ & $\begin{array}{c}\text { Film- } \\
\text { coated GC }\end{array}$ & \\
\hline NO $(87.5 \mu \mathrm{M})$ & $2.49^{*}$ & 2.32 & 0.9 \\
Nitrite $(1 \mathrm{mM})$ & 32.41 & $2.60 \times 10^{-3}$ & $\sim 10^{-4}$ \\
Ascorbic Acid $(1 \mathrm{mM})$ & 12.12 & $2.70 \times 10^{-3}$ & $\sim 10^{-4}$ \\
Uric Acid $(1 \mathrm{mM})$ & 16.52 & $2.70 \times 10^{-3}$ & $\sim 10^{-4}$ \\
Dopamine $(1 \mathrm{mM})$ & 14.71 & $1.03 \times 10^{-2}$ & $\sim 10^{-3}$ \\
\hline
\end{tabular}

*Nafion (16 $\mu \mathrm{m})$ was coated. 
Amperometric Detection of Nitric Oxide

By using the triply polymer-coated GC electrode, amperometric detection of nitric oxide in deoxygenated phosphate buffer with $\mathrm{pH}=7.4$ was carried out. Aliquots of phosphate buffer saturated with $5 \% \mathrm{NO}(87.5 \mu \mathrm{M})$ was successively injected into the cell containing $10 \mathrm{ml}$ phosphate buffer to attain $87.5 \mathrm{nM} \sim 878 \mathrm{nM}$. The potential of the working electrode was maintained at $0.9 \mathrm{~V}$ (vs. Ag|AgCl). Figure 4 shows typical amperograms measured at triply polymer film-coated GC electrode with successive addition of NO.

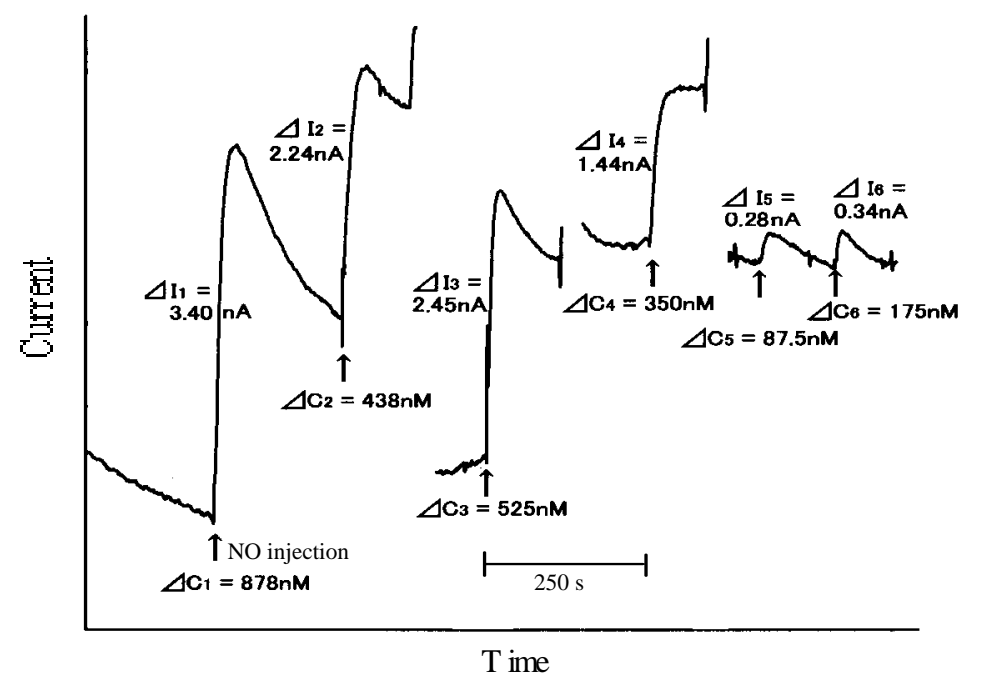

Figure 4. Typical amperograms measured at a GC|Nafion $(16 \mu \mathrm{m}) \mid$ PADDA $(5 \mu \mathrm{m}) \mid$ silicone $(15 \mu \mathrm{m})$ electrode with successive injection of NO.

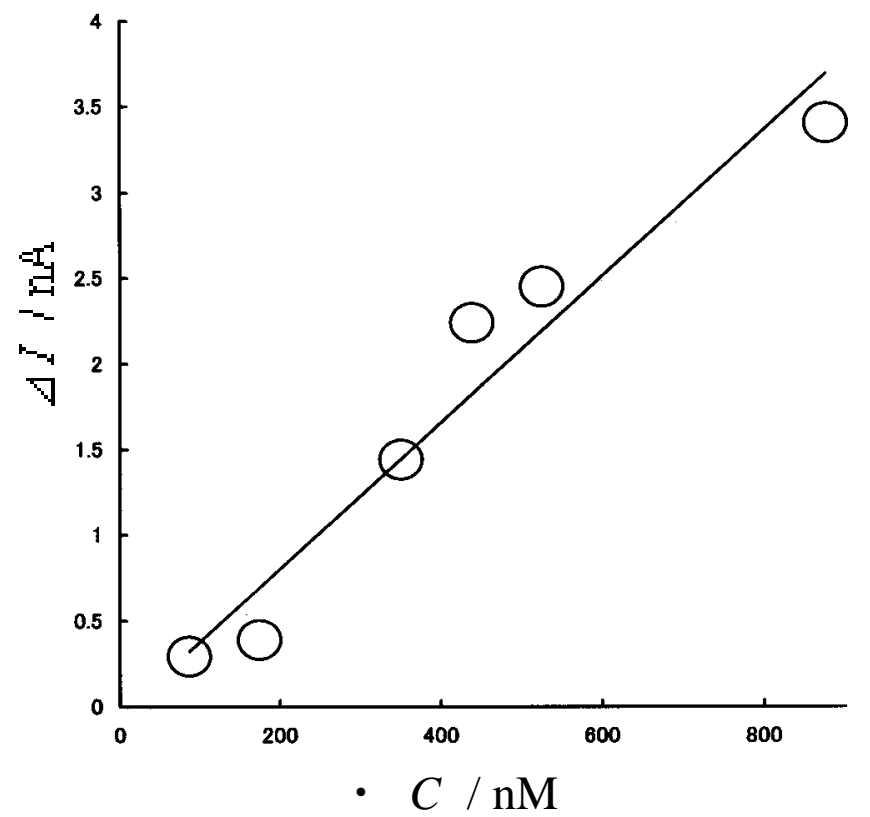

Figure 5. Detection curve of NO obtained by amperometry at a GC|Nafion (16 $\mu \mathrm{m}) \mid$ PADDA (5 $\mu \mathrm{m}) \mid$ silicone $(15 \mu \mathrm{m})$ electrode. 
These amperograms clearly show an increase in oxidation currents with NO injections. The relation between the increment of current after injection and that of NO concentration was roughly linear in the range of concentrations investigated, as shown in Figure 5. The limit of NO detection at a GC electrode coated only with $16 \mu \mathrm{m}$ Nafion (Fe-TPFPP) film was $18 \mathrm{nM}$ [18]. Although the limit became high by the triple layer polymer coating, $\mathrm{NO}$ of $80 \mathrm{nM}$ was detected by the present electrode. Time elapsed before peak current after NO injection in Fig. 4, so-called response time, was roughly $15 \mathrm{~s}$. This time also became longer, compared with $1 \sim 2 \mathrm{~s}$ at a GC | Nafion (16 $\mu \mathrm{m})$ electrode [18]. A higher detection limit of $\mathrm{NO}$ at the present electrode seems to result from longer response time through increased film thickness. It took about 30 min for the measurement of amperograms in Fig. 4. In the second and third cycles after exchanging the electrolytic solution, we observed almost the same amperograms as those in the first one. Stability and reproducibility of NO detection by this electrode were fairly good, but we did not check long-term stability.

\section{Catalysis by Fe(TPFPP) for NO Oxidation}

Various iron porphyrins have been clarified to show catalytic activity for nitric oxide oxidation [18]. Especially, water-soluble iron porphyrin, iron(III) meso-tetrakis(N-methylpyridinium-4-yl) (Fe(TMPyP)), showed a selective oxidation of NO against nitrite. This selectivity has been ascribed to different catalyses by different high-valent iron complexes, namely oxo-iron(IV) for NO oxidation to nitrite and oxo-iron(IV) $\pi$-cation radical for nitrite oxidation to nitrate [21].

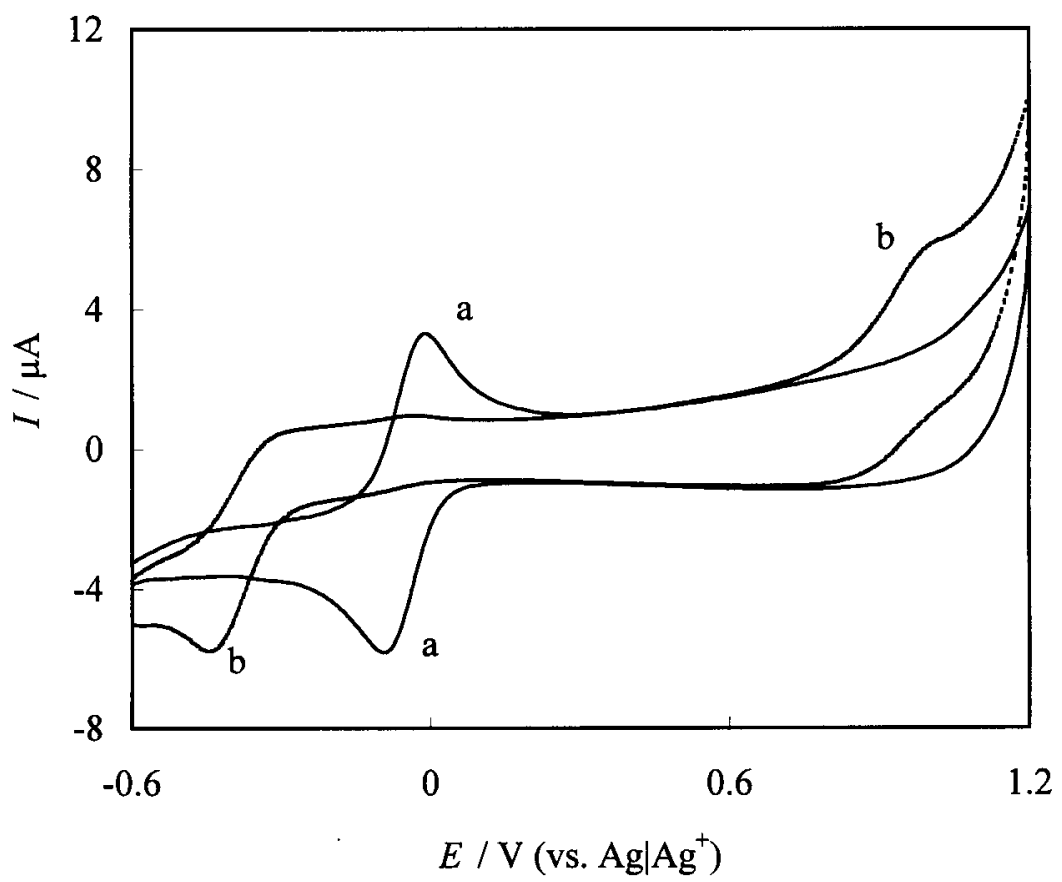

Figure 6. Cyclic voltammograms of $4 \times 10^{-4} \mathrm{M}$ Fe(TPFPP)Cl at a GC electrode in $0.1 \mathrm{M}$ TBAP methanol solution (a) without and (b) with $4 \times 10^{-4} \mathrm{M}$ tetrabutylammonium hydroxide. Scan rate, $100 \mathrm{mV} \mathrm{s}^{-1}$. 
It is not so easy to clarify the catalysis of water-insoluble Fe(TPFPP) in Nafion film being insulator. So, it was examined to estimate the catalysis by dissolving Fe(TPFPP) into methanol. Figure 6 shows the cyclic voltammograms of $\mathrm{Fe}(\mathrm{TPFPP})$ in methanol with and without tetrabutylammonium hydroxide $\left(\mathrm{Bu}_{4} \mathrm{NOH}\right)$. In pure methanol (Fig. 6a), the cyclic voltammogram was simple. It showed one $\mathrm{Fe}^{3+} / \mathrm{Fe}^{2+}$ redox at $-0.05 \mathrm{~V}$ (vs. $\mathrm{Ag} \mid \mathrm{Ag}^{+}$) and the porphyrin ring oxidation above $1.05 \mathrm{~V}$ (vs. $\mathrm{Ag} \mid \mathrm{Ag}^{+}$). On the other hand, the cyclic voltammogram in the presence of hydroxide (Fig. 6b) was complicated. It showed $\mathrm{Fe}^{3+} / \mathrm{Fe}^{2+}$ redox at more negative potential, compared with that in pure methanol. This suggested that electron-donating species (hydroxide) ligated to the iron site. In addition to this negative shift of the redox potential, the cyclic voltammogram showed a new distorted redox at $0.9 \mathrm{~V}$ before the ring oxidation. This characteristic was very close to that observed at water-soluble Fe(TMPyP) [22]. Formation of oxo-iron(IV) (TPFPP) was estimated before the ring oxidation.

When NO was introduced into the solution of $\mathrm{Fe}(\mathrm{TPFPP})$ containing $\mathrm{Bu}_{4} \mathrm{NOH}$, the $\mathrm{Fe}^{3+} / \mathrm{Fe}^{2+}$ redox was disappeared and two oxidation peaks appeared as can be seen in Fig. 7. In analogy with Fe(TMPyP), the disappearance of the redox can be explained by the reductive nitrosylation, namely the formation of Fe(II)(NO) complex. The first oxidation peak corresponding to 1-electron oxidation at $0.55 \mathrm{~V}$ [23] can be ascribed to the oxidation of $\mathrm{Fe}(\mathrm{II})(\mathrm{NO})$ to $\mathrm{Fe}(\mathrm{III})+\mathrm{NO}$. The second large oxidation peak is due to oxidation of free NO. Agreement of the onset potentials of NO oxidation (Fig. 7a) and oxo-iron(IV) formation (Fig. 7b), and also an increase in the NO oxidation current by the presence of Fe(TPFPP) (Fig. 7a and Fig. 7c) suggest EC catalytic cycle as in the case of Fe(TMPyP) in aqueous solution [22].

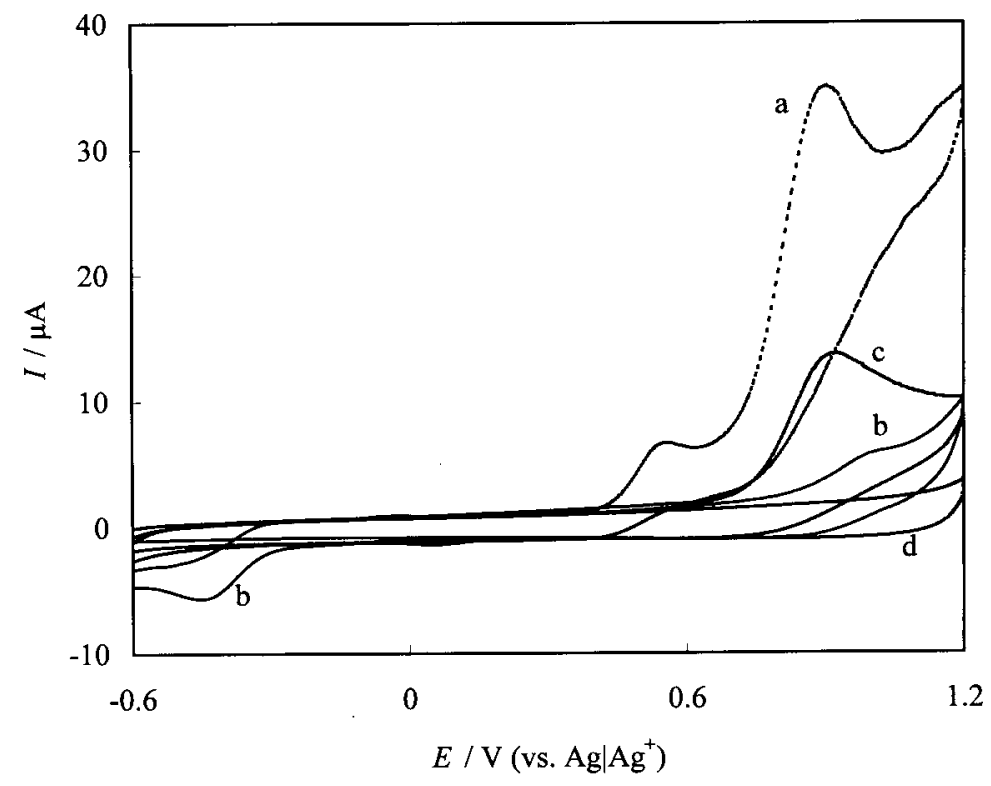

Figure 7. Cyclic voltammograms of $4 \times 10^{-4} \mathrm{M}$ Fe(TPFPP)Cl at a GC electrode in $0.1 \mathrm{M}$ TBAP methanol solution (a) saturated with 5\% NO and (b) without NO. Curves (c) and (d) are obtained in 0.1 M TBAP methanol solution saturated with 5\% NO and without NO, respectively. Scan rate, $100 \mathrm{mV} \mathrm{s}^{-1}$. 


$$
\begin{aligned}
& \left(\mathrm{HO}^{-}\right) \mathrm{Fe}(\mathrm{III})-\mathrm{e}^{-} \rightarrow \mathrm{O}=\mathrm{Fe}(\mathrm{IV})+\mathrm{H}^{+} \\
& \mathrm{O}=\mathrm{Fe}(\mathrm{IV})+\mathrm{NO}+\mathrm{OH}^{-} \rightarrow\left(\mathrm{HO}^{-}\right) \mathrm{Fe}(\mathrm{III})+\mathrm{NO}_{2}{ }^{-}
\end{aligned}
$$

The distribution of Fe(TPFPP) in Nafion film, which was doped by dissolving into Nafion solution, is not so simple. A 2/3 of water-insoluble $\mathrm{H}_{2}$ TPP has been found to distribute in hydrophilic ion channels and the other $1 / 3$ in hydrophobic region of Nafion film [24]. If Fe(TPFPP) was distributed in hydrophilic region, it is surrounded by water molecules and may form hydroxo-complex, (HO־)Fe(III).

\section{References and Notes}

1. Palmer, R. M. J.; Ferrige, A. G.; Moncada, S. Nitric oxide release accounts for the biological activity of endothelium-derived relaxing factor. Nature 1987, 327, 524-526.

2. Ignarro, L. J.; Buga, G. M.;Wood, K. S.; Byrns, R. E.; Chaudhuri, G. Endothilium-derived relaxing factor produced and released from artery and vein is nitric oxide. Proc. Natl Acad. Sci. U.S.A. 1987, 84, 92659269.

3. Butler, A. R.; Williams, D. L. H. The physiological role of nitric oxide. Chem. Soc. Rev. 1993, 1993, 233241.

4. Liew, F. Y.; Li, Y.; Moss, D.; Parkinson, C.; Rogers, M. V.; Moncada, S. Resistance to Leishmania major infection correlates with the induction of nitric oxide synthase in murine macrophages. Eur. J. Immunol. 1991, 21, 3009.

5. Archer, S. Measurement of nitric oxide in biological models. FASEB J. 1993, 7, 349-360.

6. Vilakazi, S. L.; Nyokong, T. Electrocatalytic properties of vitamin $\mathrm{B}_{12}$ towards oxidation and reduction of nitric oxide. Electrochim. Acta 2000, 46, 453-461.

7. Palimini, M.; Culluri,A.; Amine, A.;Palleschi, G. Amperometric nitric oxide sensor: a comparative study. Electroanalysis 1998, 10, 1010-1016.

8. Shibuki, K. Detection of nitric oxide by an electrochemical microprobe. Neuroprotocols 1992, 1, 151-157.

9. Bedioui, F; Villeneuve, N.Electrochemical nitric oxide sensors for biological samples-principle, selected examples and applications. Electroanalysis, 2003, 15, 5-18.

10. Chang, X.; Lin, J.; Cardosa, L.; Broderick, M.; Darley-Usmar, A novel microchip nitric oxide sensor with sub-nM detection limit, Electroanalysis, 2002, 14, 697-703.

11. Malinski, T.; Taha, Z. Nitric oxide release from a single cell measured in situ by a porphyrinic-based microsensor. Nature 1992, 358, 676-678.

12. Mizutani, F.; Hirata, Y.; Yabuki, S; Iijima, S. Amperometric measurement of nitric oxide (NO) using an electrode coated with polydimethylsiloxane. Chem. Lett. 2000, 2000, 802-803.

13. Bedioui, F.; Boucher, Y.; Sorel, C.; Devynck, J.; Coche-Guerente, L.; Deronzeir., A.; Moutet, J. C, Incorporation of anionic metalloporphyrins into poly(pyrrole-alkylammonium) films - Part 2 Characterization of the reactivity of the iron(III) porphyrinic-based polymer. Electrochim. Acta 1993, 38, 2485-2491 
14. Wink, D. A.; Christodoulou, D.; Ho, M.; Chrishna, J. A.; Cook, J. A.; Haut, H.; Randolph, J. K.; Sullivan, M.; Coia, G.; Murray, R.; Meyer, T. A discussion of electrochemical techniques for the detection of nitric oxide. Methods (San Diego), 1995, 7, 71-77.

15. Lantoine, F.; Trevin, S.; Bedioui, F.; Devynck, J. Selective and sensitive electrochemical measurement of nitric oxide in aqueous solution: discussion and new results. J. Electroanal. Chem. 1995, 392, 85-89.

16. Trevin, S.; Bedioui, F.; Devynck, J. New electropolymerized nickel porphyrin films. Application to the detection of nitric oxide in aqueous solution. J. Electroanal. Chem. 1996, 408, 261-265.

17. Citzewski, A.; Kubaszewski, E.; Lozynski, L. The role of nickel as central metal in conductive polymeric porphyrin film for electrocatalytic oxidation of nitric oxide. Electroanalysis 1996, 8, 293-295.

18. Kitajima, A.: Miyake, M.; Kobayashi, T.; Koyama, H.; Ikeda. O.; Kijima, K.; Komura, T. Uno, A.; Yamatodani, A. Detection of nitric oxide with the iron(III) porphyrin doped Nafion $\mid$ glassy carbon electrode. Electrochemistry 1999, 67, 784-788.

19. Kashevskii, A. V.: Safronov, A. Y.; Ikeda, O. Behaviours of $\mathrm{H}_{2} \mathrm{TPP}$ and CoTPPCl in Nafion ${ }^{\mathrm{R}}$ film and the catalytic activity for nitric oxide oxidation J. Electroanal. Chem. 2001, 510, 86-95.

20. Chen, J.; Ikeda, O.; Hatasa, T.; Kitajima, A.; Miyake, M.; Yamatodani, A. Oxidation of NO mediated by water-soluble iron porphyrin. Electrochem. Commun. 1999, 1, 274-277.

21. Lei, J.; Ju, H.; Ikeda, O. Catalytic oxidation of nitric oxide and nitrite mediated by water-soluble highvalent iron porphyrins at an ITO electrode. J. Electroanal. Chem. 2004, 567, 331-338.

22. Lei, J.; Trifimova, N. S.; Ikeda. O. Selective oxidation of nitric oxide against nitrite by oxo-iron(IV) porphyrin at an ITO electrode. Chem. Lett. 2003, 32, 610-611.

23. Trofimova, N. S.; Safronov, A. Y.; Ikeda, O. Electrochemical and spectral studies on the reductive nitrosylation of water-soluble iron porphyrin. Inorg. Chem. 2003, 42, 1945-1951.

24. Kashevskii, A. V.; Lei, J.; Safronov, A. Y.; Ikeda, O. Electrocatalytic properties of mesotetraphenylporphyrin cobalt for nitric oxide oxidation in methanolic solution and in Nafion film. $J$. Electroanal. Chem. 2002, 531, 71-79.

(C) 2005 by MDPI (http://www.mdpi.net). Reproduction is permitted for noncommercial purposes. 